\title{
Intrarenal Color Doppler Ultrasonography in the Diagnosis of Accessory Renal Artery Stenosis
}

\author{
Rauniyar RK ${ }^{1}$, Srivastava $\mathrm{DN}^{2}, \mathrm{Bal} \mathrm{CS}^{3}$, Dash $\mathrm{SC}^{4}$, Berry $\mathrm{M}^{2}$ \\ ${ }^{1}$ Department of Radiodiagnosis, BPKIHS, Dharan, Nepal, ${ }^{2}$ Department of Radiodiagnosis, \\ ${ }^{3}$ Department of Nuclear Medicine, ${ }^{4}$ Department of Nephrology, AIIMS, New Delhi, India
}

\begin{abstract}
Conventional color Doppler ultrasonography of main renal artery is a valuable non invasive tool in screening and diagnosing patients with renal artery stenosis. However, this technique suffer a set back from many limitations. Color Doppler ultrasonography examination of intrarenal branch arteries using the parameters like, acceleration time, acceleration time ratio, and acceleration index with additional sampling from upper and lower pole of kidney has shown good results in diagnosis of renal artery stenosis. We successfully diagnosed accessory renal artery stenosis in two patients using intrarenal Doppler technique. We conclude, intra renal Color Doppler ultrasonography with additional sampling from upper and lower pole is most accurate method for diagnosis of significant RAS including accessory RAS.
\end{abstract}

Keywords: Color Doppler Ultrasonography, Accessory renal artery stenosis, Digital Subtraction angiography, Intra renal Doppler.

\section{Introduction}

Color Doppler ultrasonography (CDUS) of main renal artery (RA) is a potentially valuable non invasive tool in screening and diagnosing patients with renal artery stenosis (RAS) are available in the literature with discordant result, sensitivity ranging from 0$91 \% .^{1-6}$ Further the study of main RA on CDUS suffer a set back from many limitations as being operator dependent, long examination time and high rate of technically

Correspondence to: Dr. R. K. Rauniyar, Professor and Head, Department of Radiodiagosis and Imaging, BPKIHS, Dharan, Nepal

Email Id: rauniyar99@yahoo.com inadequate studies secondary to obesity or overlying bowel gas. ${ }^{1,2}$ The direct CDUS study of main RA also posses problem of studying the entire course of RA and there is difficulty in identifying the accessory RA and hence any stenosis of accessory arteries can be easily missed. Therefore there is need for indirect CDUS study of intrarenal, branch arteries which will reflect the hemodynamic changes distal to the stenosis. Few studies are available in literature highlighting the hemodynamic changes distal to the stenosis causing alteration in waveform known as parvus tardus effect. ${ }^{7-9}$ This effect consists of post stenotic alternation in which a wave of lower amplitude is observed with longer time to reach the peak systolic velocity. ${ }^{8} \mathrm{We}$ present two cases of renovascular 
Table 1: Table showing value of AT, ATR, AI and characteristic of spectral trace from mid portion, upper and lower pole of kidneys in two patients

\begin{tabular}{|c|c|c|c|c|c|}
\hline Cases & Side & $\begin{array}{l}\text { CDUS } \\
\text { Parameters }\end{array}$ & Upper pole & Mid portion & Lower Pole \\
\hline \multirow[t]{8}{*}{ Case 1} & \multirow[t]{4}{*}{ Left } & AT & 0.42 & 0.44 & 0.40 \\
\hline & & ATR & 7.50 & 8.00 & 8.20 \\
\hline & & AI & 2.00 & 2.50 & 2.20 \\
\hline & & SP Trace & $\begin{array}{l}\text { Parvus } \\
\text { Tardus }\end{array}$ & $\begin{array}{l}\text { Parvus } \\
\text { Tardus }\end{array}$ & $\begin{array}{l}\text { Parvus } \\
\text { Tardus }\end{array}$ \\
\hline & \multirow[t]{4}{*}{ Right } & AT & 0.40 & 0.06 & 0.06 \\
\hline & & ATR & 8.00 & 1.00 & 1.00 \\
\hline & & AI & 1.40 & 4.00 & 3.8 \\
\hline & & Sp Trace & $\begin{array}{l}\text { Parvus } \\
\text { Tardus }\end{array}$ & Normal & Normal \\
\hline \multirow[t]{4}{*}{ Case 2} & \multirow[t]{4}{*}{ Left } & $\mathrm{AT}$ & 0.06 & 0.40 & 0.08 \\
\hline & & ATR & 1.25 & 8.00 & 1.60 \\
\hline & & AI & 4.0 & 1.25 & 3.6 \\
\hline & & Sp Trace & Normal & $\begin{array}{l}\text { Parvus } \\
\text { Tardus }\end{array}$ & Normal \\
\hline
\end{tabular}

AT: Acceleration time in seconds, ATR: Acceleration time ratio, AI: Acceleration index in meter $/ \mathrm{sec}^{2}$, Sp Trace: spectral trace.

hypertension due to accessory RAS, Case I

diagnosed on intrarenal CDUS with additional sampling from upper and lower pole, using parameters acceleration time (AT), acceleration time $\operatorname{ratio}(\mathrm{ATR})$, and acceleration index(AI).

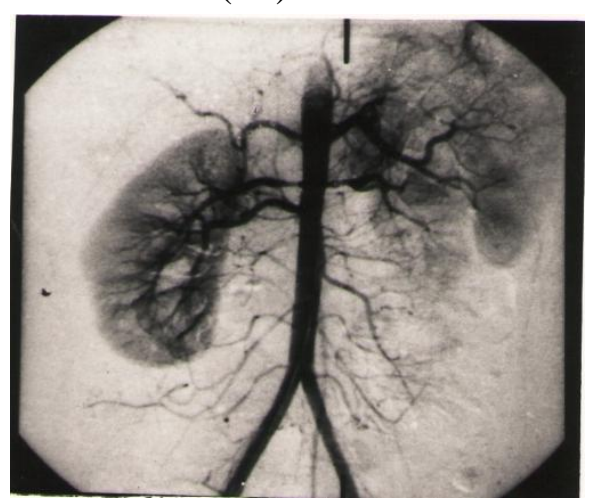

Fig 1a : Digital substraction angiography showing right accessory renal artery stenosis supplying upper pole of kidney and left main RAS.

A 22- year female detected to have hypertension during her routine antenatal check up. Her hypertension of 180/110 mm of $\mathrm{Hg}$ persisted even after delivery. Routine laboratory examinations including renal function tests were within normal limit. She continued to have elevated blood pressure inspite of multidrug antihypertensive therapy. Being young patient, secondary hypertension due to RAS was suspected. Ultrasonography of abdomen and pelvis did not reveal any abnormality except left kidney was slightly smaller $(8.2 \mathrm{~cm})$ compared to right kidney $(9.4 \mathrm{~cm})$. Intrarenal vessels were indentified with add of color flow and Doppler tracing was obtained from both kidneys. The spectral trace obtained from left 


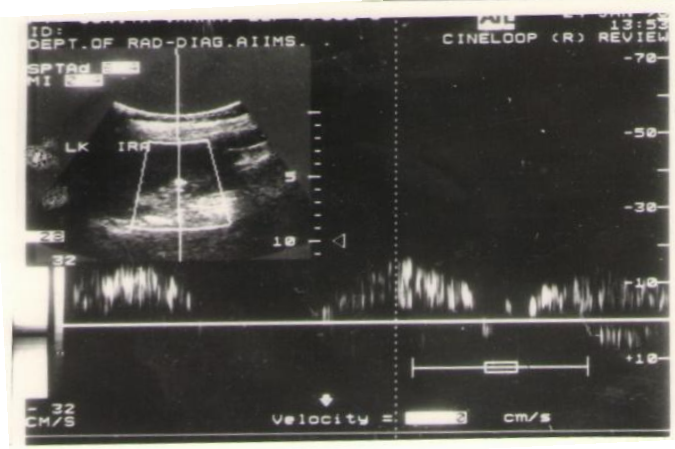

Fig 1b : Doppler tracing from intrarenal branch artery of left kidney showing parvus tardus pattern of wave form with markedly elevated acceleration time suggesting RAS.

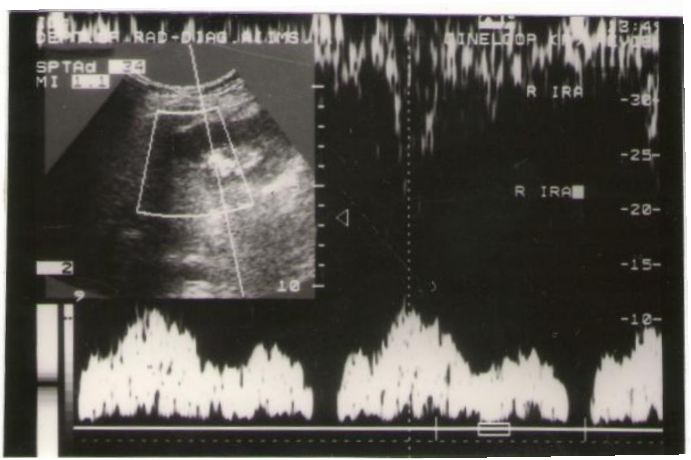

Fig 1c : Intrarenal branch artery Doppler tracing from upper pole of right kidney showing purvus tradus pattern of waveform.

kidney around renal sinus showed parvus tardus pattern of wavefrom with markedly prolonged values of AT and ATR and diminished value of AI. Similar pattern of wavefrom was also seen from upper and lower pole tracing. The spectral trace obtained from right kidney around renal sinus lower pole showed normal pattern of wave form with normal parameter values, while spectral trace obtained from upper pole showed parvus tardus pattern of waveform with elevated values of AT $<$ ATR and lowered value of AI (Table 1). Based on these abnormal parameters, a diagnosis of left RAS and right accessory artery stenosis supplying upper pole of kidney was made, which was confirmed on DSA (Fig 1.a-c).

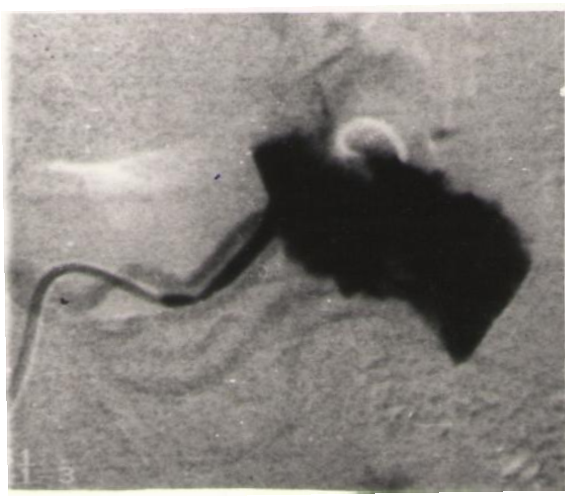

Fig 2a : Selective left renal angiogram ahowing short segment stenosis of renal artery supplying only mid portion of kidney.

\section{Case II}

A 48 year female was diagnosed to have hypertension, not controlled with single antihypertensive. Routine laboratory examination did not reveal any abnormalities, however, chest radiographs showed mild cardiomegaly. Fundus examination revealed grade II hypertensive retinopathy. On the basis of history of refractory hypertension and grade II retinopathy she was evaluated for secondary causes of hypertension. Ultrasonography of abdomen and pelvis did not reveal any abnormality. Intrarenal CDUS of right kidney with additional sampling from upper and lower poles showed normal low resistance spectral trace with normal AT, ATR and AI. Intrarenal CDUS of left kidney showed parvus tardus pattern of waveform from the tracing obtained from mid portion of kidney while lower pole tracing showed borderline changes in AT, ATR and AI, however tracing from upper pole of kidney was normal (Table 1). On the basis of these abnormal values, a diagnosis of left accessory RAS supplying mid portion of kidney and junctional region of portion and 
lower pole was made. These findings were conformed on DSA (Fig 2a-c).

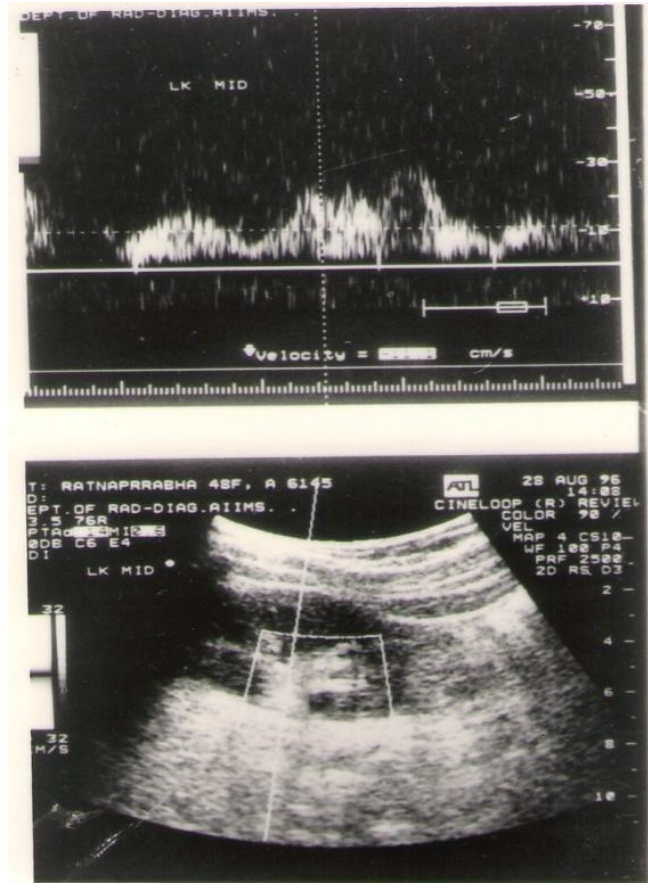

Fig 2b : Doppler tracing from mid portion of left kidney showing parvus tardus pattern of waveform suggesting RAS.

\section{Discussion}

The reported frequency of multiple/accessory renal artery widely from 2.8 to $15 \% .^{8,10,11}$ No data is available to highlight the percentage of stenosis of accessory RA among those who have RVH due to RAS. Martin RL et al reported 15\% incidence of multiple RA and observed that stenosis of accessory RA was responsible for more than one third of their false negative cases on CDUS of renal hilar vessels in detection of RAS. ${ }^{10}$ In their study they only obtained a single sample from centre of renal sinus. Recent reports with intrarenal branch arteries doppler waveform analysis with additional sampling from upper and lower pole had shown much improved resilts. $^{7,8}$ The efficacy of this additional sampling for diagnosis of accessory RAS was not established in the series of Stavros
AT et al as in their series none of the accessory artery present was stenosed ${ }^{8}$ Later on a case report validating this technique of diagnosing accessory RAS on intrarenal CDUS was published by Hall NJ et al. ${ }^{12}$

In the present report of 2 cases we also obtained tracing around renal sinus with additional sampling from upper and lower pole of each kidney. The intrarenal Doppler parameters used were AT $\leq 0.06 \mathrm{sec}, \mathrm{ATR} \leq$ 1.5 and $\mathrm{AI} \geq 3.6 \mathrm{~m} / \mathrm{sec}^{2}$ with normal low resistance spectral trace which were obtained from control group of patients by us (Rauniyar RK, unpublished data of year 1997). However Handa N et al have defined the normal range of Doppler parameters and these were close to our value as $\mathrm{AT} \leq$ $0.07 \mathrm{sec}, \mathrm{ATR} \leq 1.35$ and $\mathrm{AI} \geq 3.78 .^{7}$ These three parameters were very accurate, because they are related to the acceleration of systolic velocity. This acceleration of systolic velocity downstream from the stenosis is mainly affected by the significant stenosis. ATR was used to rule out effect of cardiac dysfunction.

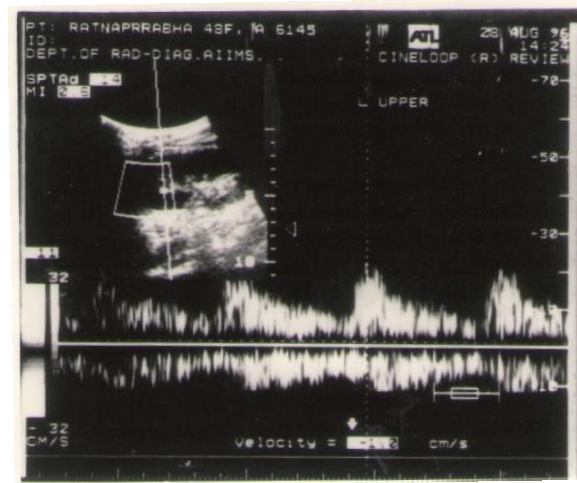

Fig 2c: Doppler tracing from upper pole of the same kidney (2b) showing normal Doppler waveform.

In case 1 , the parameter namely AT, ATR, and AI and spectral trace were abnormal in the left side from all the tracing obtained around renal sinus, upper and lower pole 
suggesting there is only one RA supplying entire left kidney and is stenosed. The tracing obtained from right kidney showed abnormal values of parameters, only of upper pole, suggesting stenosis of artery supplying upper pole of kidney. While mid portion and lower pole tracings were normal suggesting normal main RA supplying these area. In case 2, abnormal doppler parameters detected accessory RA stenosis supplying mid portion and junctional region between mid portion and lower pole. While two other arteries supplying lower and upper pole was normal, this was later confirmed on DSA. Though the RA supplying midportion of kidney was main RA and other two were accessory RA, but on Doppler parameters, we could successfully say that there were three RA supplying this kidney and the artery supplying mid portion of kidney is stenosed. This highlights usefulness of this technique of intrarenal CDUS with additional sampling from upper pole and lower pole in diagnosis of accessory RAS.

\section{Conclusion}

In conclusion, intrarenal CDSU with additional sampling from upper pole and lower pole of kidney using parameters AT, ATR, and AI is a accurate method for diagnosis of renal artery stenosis including accessory RAS. There is a need for a future study comprising large number of cases with accessory RAS to further validate this technique for diagnosis of accessory RAS.

\section{References}

1. Desberg AL, Pauster DM, Lammert GK, Hale JC, Troy RB, Novick AC, et al.Renal artery stenosis evaluation with colour Doppler flow imaging. Radiology. 1990; 177:749-53.
2. LL Berkand, DB Koslin, Routh and FS Keller. Renal artery stenosis: prospective evaluation of diagnosis with color duplex US compared with angiography. Radiology 1990; 174:421-23.

3. Kohler TR, Zierler RE, Martin RL, Nicholls SC, Bergelin RO, Kazmers A, et al.Non invasive diagnosis of renal artery stenosis by ultrasonic duplex scanning. $\mathbf{J}$ Vasc Surg. 1986; 4:450-6.

4. Miralles M, Santiso A, Gimenzez A, Riambau V, Saez A, Daumal J, et al. Renal diplex scanning correlation with angiography and isotopic renography. Eur J Vasc Surg. 1993; 7:188-94.

5. Zoller WG, Harmans H, Bogner JR, Hahn D, Middeke M.. Duplex sonography in the diagnosis of renovascular hypertension. Klin Wochenscher. 1990; 68:830-4.

6. Strandness DE Jr. Duplex scanning in diagnosis of renovascular hypertension. Surg Clin North Am. 1990; 70:109-17.

7. Handa N, Fukunaga R, Etani H, Yoneda S, Kimura K, Kamada T. efficacy of echo-doppler examination for the evaluation of renovascular diseases. Ultrasound Med Biol. 1988; 70:109-17.

8. Stavros AT, Parker SH, Yakes WF, Chantelois AE, Burke BJ, Meyers PR et al. Segmental stenosis of the renal artery: pattern recognition of tardus and parvus abnormality with duplex sonography. Radiology. 1992; 184:487-92.

9. Kliewer MA, Tupler RH, Carroll BA, Paine SS, Kriegshauser JS, Hertzberg 
BS, et al. renal artery stenosis: analysis of Doppler wave form parameters and tardus. Parvus pattern. Radiology. 1993; 189:779-87.

10. Matrin RL, Nanra RS, Wlodarezyk J, Desilva A, Bray AE. Renal hilar Doppler analysis in the detection of renal artery stenosis. J Vas Technol 1991; 15:173-80.

11. CT Posrma, J van Aalen, $\mathrm{T}$ de Boo, G Rosenbusch and $\mathrm{T}$ Thien. Doppler ultrasound scanning in the detection of renal artery atenosis in hypertensive patients. Br JRadiology 1992; 65:857860.

12. Hall NJ, Thorpe RJ, Mackechnie SG. Stenosis of accessory renal arter: Doppler ultrasound finding. Australas Radiol 1995; 39:73-77. 